\title{
Costs and Benefits of Facebook for Undergraduate Students
}

\author{
Ruti Gafni \\ Tel Aviv-Yaffo Academic College \\ and Open University of Israel, \\ Tel Aviv, Israel
}

rutigafn@mta.ac.il

\author{
Moran Deri \\ Tel Aviv-Yaffo Academic \\ College, \\ Tel Aviv, Israel
}

momorr3@gmail.com

\begin{abstract}
Originally, the Facebook network was meant for students' use on campus, but is it worthwhile for them? Facebook is a broad source of information for students, offering correspondence between students, providing files and information exchange, and allowing new acquaintances on campus. On the other hand, Facebook includes a variety of distractions, such as uploading pictures, viewing profiles, videos, and photos of friends, chatting with friends, and playing, which lead to procrastination and injures the learning process. The present study was conducted in order to examine the influence of Facebook on the students' learning process in undergraduate demanding faculties, such as engineering. In particular, it was aimed at identifying various costs and benefits associated with the students' use of Facebook and investigating the impact of the colleges/schools' Facebook pages on the students' use of Facebook for learning purposes. A questionnaire was filled in by undergraduate students, and Facebook pages of academic institutions were examined. Facebook was found to be particularly important among first year students, benefiting their social absorption in the campus and their learning sources, but these benefits were reduced for senior year students. However, it was found that social activities on Facebook consumed a significant amount of the students' time, during the surfing and even after, thus negatively affecting their learning process. Moreover, the majority of the examined Facebook pages that were opened on the initiative of academic institutions were mostly inactive, giving no benefits to students and no incentive to use them.
\end{abstract}

Keywords: Facebook, social networks, learning, costs, benefits.

\section{Introduction}

Educational institutions and students use the Internet in general and online social networks in particular as tools to convey information. One of the communication tools used by many students in

Material published as part of this publication, either on-line or in print, is copyrighted by the Informing Science Institute. Permission to make digital or paper copy of part or all of these works for personal or classroom use is granted without fee provided that the copies are not made or distributed for profit or commercial advantage AND that copies 1) bear this notice in full and 2) give the full citation on the first page. It is permissible to abstract these works so long as credit is given. To copy in all other cases or to republish or to post on a server or to redistribute to lists requires specific permission and payment of a fee. Contact Publisher@InformingScience.org to request redistribution permission. their daily life is Facebook. In recent years, Facebook has been adopted extensively for educational purposes (e.g., see Boon and Sinclair, 2009; Hendrix, Chiarella, Hasman, Murphy, \& Zafron, 2009).

Facebook is an online social network initially started by a group of students at Harvard University and subsequently expanded all over the world, becoming 
the largest social network worldwide (Kirkpatrick, 2010). Today, it has more than 845 million active users - users who accessed the website in the past 30 days (Facebook Newsroom, 2012) and for whom using Facebook has become an integral part of their everyday life.

Facebook enables people to create profiles that comprise their personal information. Facebook users connect to other users, called "friends". Each user owns a "wall" that shows the user's updates, comments, uploaded photographs, and more. Users can exchange information using the "wall" by sending messages or by using instant chat. Furthermore, users can create online networks of friends and join groups of individuals sharing common interests, common ground, or particular themes (Mack, Behler, Roberts, \& Rimland, 2007). In addition, it is possible to upload files and to correspond through personal or general messages. With all these features, Facebook allows educational institutions and students to create a central platform for media sharing, communications around social and academic issues, and drawing the community's awareness of certain subjects.

Facebook can be useful for students in their social life as well as for academic purposes, as it allows for activities such as getting assistance or sharing notes. There are also disadvantages in using Facebook, such as waste of time (Ulusu, 2010), procrastination and changing priorities (Vivian, 2011), waste of money (because of additional expenses for surfing), and even addiction (Kuss \& Griffiths, 2011; Ulusu, 2010).

This research examines the perceived costs and benefits of using Facebook by undergraduate students in demanding faculties, such as students of engineering. The purpose of this study is to analyze and reveal the various costs and benefits that students have in using Facebook. This paper includes a background about previous studies in this field, the presentation of the research questions, explanation of the methodology used to examine these questions, exhibition of the results, a discussion about the significance of the results, and finally the conclusions from the research.

\section{Background}

Previous research work concerning Facebook and students was focused on themes such as emotional effects, such as jealousy and self-esteem (Gonzales \& Hancock, 2011; Orr et al., 2009), social adjustment (Pempek, Yermolayeva \& Calvert, 2009), addiction (Kuss \& Griffiths, 2011), relationship between students and their faculty (Boogart, 2006; Hew, 2011; Madge, Meek, Wellens, \& Hooley, 2009), adoption of the social media technology and daily use of Facebook (Wheeler, 2011), and main activities of students on Facebook.

The adoption of Facebook among students grows along the years. Hewitt and Forte (2006) found that $79 \%$ of the students were connected to Facebook. In 2007 the usage increased to 94\% (Ellison, Steinfield, \& Lampe, 2007); according to the results of the present study, 96\% of the students who answered the questionnaire were connected to Facebook. From these statistics, it is clear that the impact of Facebook on students has increased, and therefore it is interesting to assess the costs and benefits associated with students' use of Facebook.

The time users invest on Facebook keeps increasing. Ellison, Steinfield, and Lampe (2007) found that $94 \%$ of the students interrogated in their research had a Facebook account and used it on average 10-30 minutes a day. Pempek et al. (2009) surveyed undergraduate students that claimed using Facebook for 30 minutes throughout the day. More recently, Kalpidou, Costin, and Morris (2011) found that students used Facebook 60-120 minutes a day. Ulusu (2010) examined key factors affecting the time users spend on Facebook and found that as people become more addicted to Facebook they tend to stay online longer, especially in order to communicate with other users. A new study (Wheeler, 2011) has found that rapid growth of social networks impacts all levels of 
the population, but the impact on students is the most dramatic. Raacke and Bonds-Raacke (2008) asked students for their opinion on why some students do not have Facebook accounts. Some of the answers were "they think it is a waste of time" (60.4\%) and "they are too busy" (70.3\%).

Various studies on Facebook usage claim that youngsters and undergraduate students use the platform mostly to stay in touch with people they already know in an offline context, instead of initiating new connections (Lampe, Ellison \& Steinfield, 2006; Pempek et al., 2009). Madge et al. (2009) argue that although students use Facebook to keep in touch with existing friends, they specifically join Facebook's university sites to enhance their social integration. Kalpidou et al. (2011) reviewed Facebook in the context of social adjustment among students and found that students in their first year on campus have a high emotional connection to Facebook. These students spent more time on Facebook and also reported having fewer friends, compared to students in second year or higher. The authors concluded that a great number of Facebook friends potentially hinder academic adaptation, and spending much time on Facebook is related to low self-esteem in the first year, but changes for senior students. Gonzales and Hancock (2011) strengthen the claim that Facebook can have either a negative or positive influence on self-esteem, according to how the person presents himself in the digital social network. This selective self-presentation influences the relationship formation and the self-esteem. In this context, Orr et al. (2009) focused on the influence of individual shyness while using Facebook and found that Facebook provides opportunities for social interaction for people who have difficulties socializing in the real world. In addition, Muise, Christofides, and Desmarais (2009) found a strong positive correlation between shyness and time spent on Facebook.

Institutions of higher education around the world began to focus on the benefits of Facebook for educational purposes (Boon \& Sinclair, 2009). Facebook was not developed to be a supportive learning environment but it has a potential to be. More and more educational institutions use social networks for academic purposes. Hewitt and Forte (2006) claimed that $33 \%$ of the students were of the opinion that their faculty should not open a Facebook account. Some researchers examined the impact of Facebook in the academy and argued that students mainly use the social network to keep in touch with other individuals, with a minimal informal academic use of Facebook for learning purposes (Hew, 2011; Madge et al., 2009). Pempek et al. (2009) found that $17 \%$ of the students who have a Facebook account use it to communicate with students from the same campus, while $50 \%$ use Facebook to communicate with off-campus friends. $35 \%$ of the students claimed they joined Facebook in order to view and post pictures. Raacke and Bonds-Raacke (2008) found that only $10.9 \%$ use Facebook for academic purposes.

\section{Research Questions}

Many of the students in engineering perceive their studies as difficult, complex, and intense and requiring a significant investment of time and efforts. Thus, the time of students is considered an expensive resource, which cannot be "wasted" by unnecessary activities on Facebook. Hence, there is a possibility that these students are active as a group on Facebook for sharing information and educational content and for supporting each other during their studies. The costs and benefits can be different between first year students and senior students. First year students are not familiar with the campus system, colleagues, teaching and learning methods, etc.; senior students in the same faculty have the potential of helping students with low self-esteem in their first steps on campus. Moreover, educational institutions have started using social networks. Many of them opened their Facebook pages where they publish information relevant to the institution, thus intending to encourage students to use Facebook for educational purposes. The main research question tries to understand the costs and benefits of using Facebook by undergraduate engineering 
students and the role that the academic institutions take in this process. This question is decomposed into a few more specific questions:

RQ-a. What do students perceive as the costs and benefits of using Facebook and which resources can be affected by their activities on Facebook?

RQ-b. Are there any differences in the use of Facebook between students who are in different stages of the learning process?

RQ-c. Do high education institutions encourage students to use Facebook?

RQ-d. Does the use of Facebook affect student' average grades?

This analysis can help to understand if Facebook fits into students' intense lives without harming their learning process and if the Facebook usage can improve student's academic performance.

\section{Methodology}

In order to analyze the worthiness of using Facebook by students, this research focuses on students enrolled in very demanding and difficult studies, who have no spare time during their studies. Therefore, the decision was to examine undergraduate students in electrical engineering faculties.

The research was performed in three steps:

1. A questionnaire - Data was gathered through an online questionnaire (see the Appendix), produced using Google Docs and distributed among 103 electrical engineering students at 4 academic institutions, in order to receive their perceptions about their usage of Facebook and the effects it has on their studies. The questionnaire was distributed through Facebook pages and groups of departments of electrical engineering. Additionally, in order to reach students who have no Facebook accounts, the questionnaire was distributed through internal academic forums, which are in use by various engineering departments and via email as well. The questionnaire was distributed to students in various phases of study (students in the first year and senior students) in order to examine if there are differences in the perceived costs and benefits among students who are at different stages of the educational process.

2. Examination of academic Facebook pages - The Facebook pages of seven engineering departments at different academic institutions were reviewed in order to understand the impact of educational institutions on Facebook use (RQ-c). The purpose was to find if the academic institutions take advantage of one of the most common tools used by students in their everyday life to establish and maintain contact with the students and provide accessibility to academic materials. The examination, which comprised the investigation of each page itself and the associated posts during six months, included, in general, the following issues:

a. Who was the initiator of the Facebook page - the faculty, the students, or the student association?

b. Who are the users who post information and respond to posts - the faculty, the students, or the student association?

c. Is the page active? A page was considered to be active if it had been used by students at least once over the previous month. We also examined how many students are involved in the conversations on the considered page.

d. Are the topics discussed academic or not?

3. Costs and benefits definition - the data accumulated was examined in order to reveal the benefits and costs of using Facebook as perceived by students. The costs and benefits analysis 
was conducted according to the methodology used for evaluating and justifying information systems and technology (Gunasekaran, Ngai, \& McGaughey, 2006). The goal was to identify different benefits students can gain from using Facebook and to identify, as well, the costs of its usage (RQ-a). The benefits were identified from the answers to the questionnaire and the examination of the study programs' pages. The benefits were classified into tangible and intangible benefits. Furthermore, using the questionnaire data, the costs of using Facebook, from the students' point of view were identified, and classified as establishment costs and operational costs.

\section{Results}

\section{Questionnaire Results}

The questionnaire was filled in by 103 undergraduate students from seven different engineering departments in four academic institutions. Almost all the participants (96\%) had a Facebook account (Q4 in Appendix); 88\% opened their account before the studies, and 8\% during their studies (Q15). Figure 1 shows the distribution of students according to their year of studies (Q1).

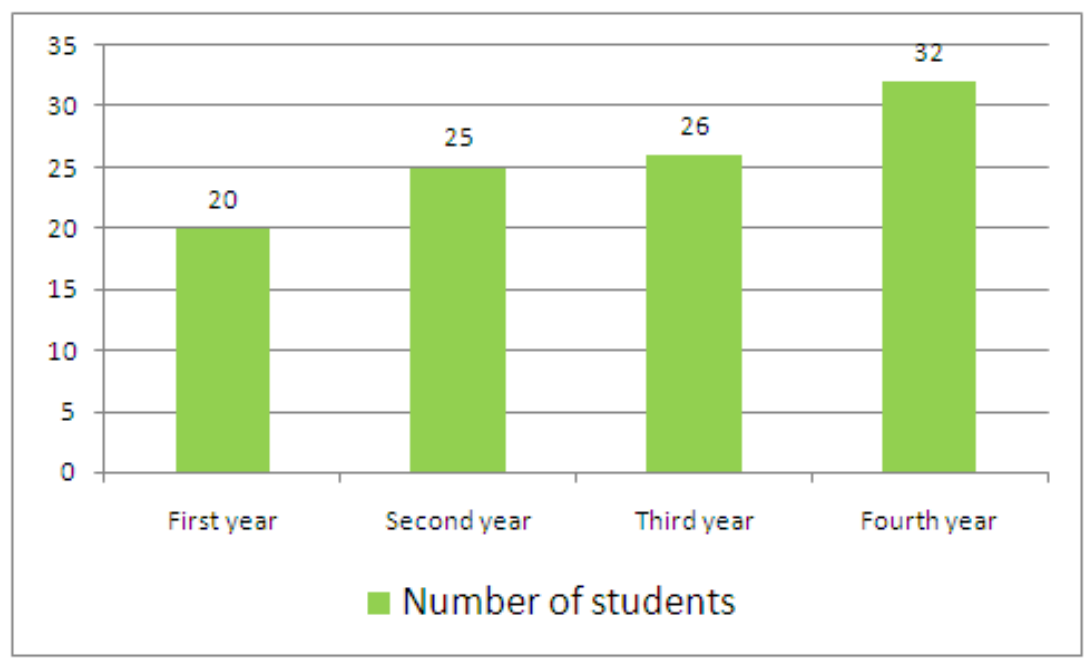

Figure 1: Number of students according to year of studies

Most of the students reported their studies are very difficult and demanding (Q2). In order to certify this declaration, they were asked about their social and recreational activities (Q3). Specifically, they were asked about the number of times in a week they were dedicating for leisure, such as going out to movies or pubs or visiting friends. (Figure 2). Our assumption here was that demanding studies do not leave enough time for these activities, even though the reason for lack of social activities may be different, as for example, part-time job (42\% of the students worked to some extent according to Q29) or family issues. 


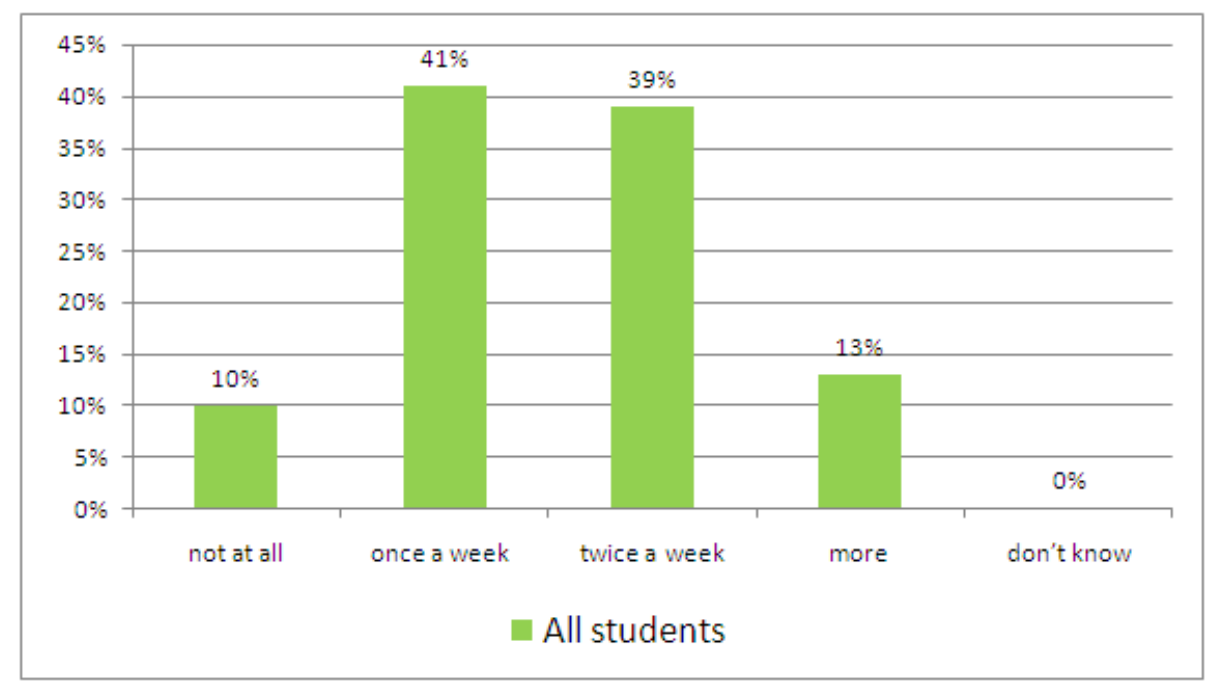

Figure 2: Number of social and recreational activities in a week

The students who had Facebook accounts were asked about their habits in using Facebook. They were asked to estimate the average number of hours they surf Facebook per day (Q5). The students' responses can be seen in Figure 3. The figure shows the distribution of all the study participants as well as the differences between first year students and senior students.

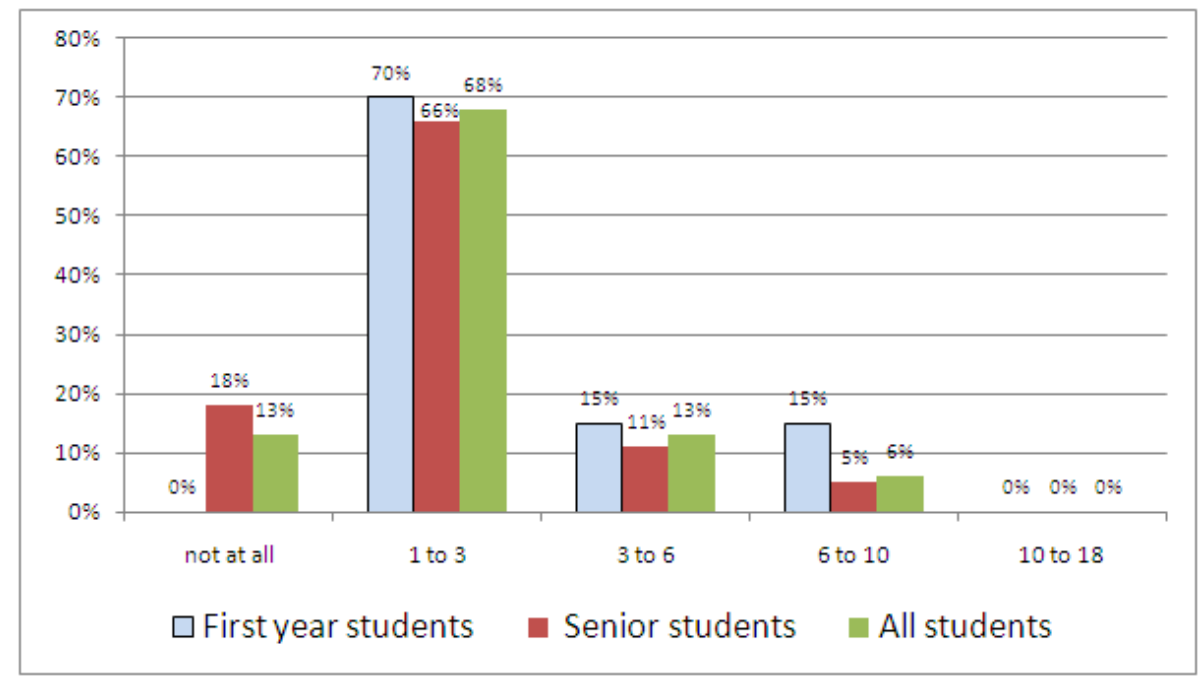

Figure 3: Average number of surfing hours on Facebook during a day

Students owning mobile phones (Q22) were asked if they browse the social network with this device; 67\% answered they do (Q23). Students without suitable phones (45\%) were asked if the possibility to browse Facebook through the phone would be a good reason to buy such a phone; 57\% answered positively (Q26).

Further, they were asked about their use of Facebook for academic purposes. The average number of "Facebook hours" used for learning activities is shown in Figure 4, showing big differences between first year and senior students (Q6). 


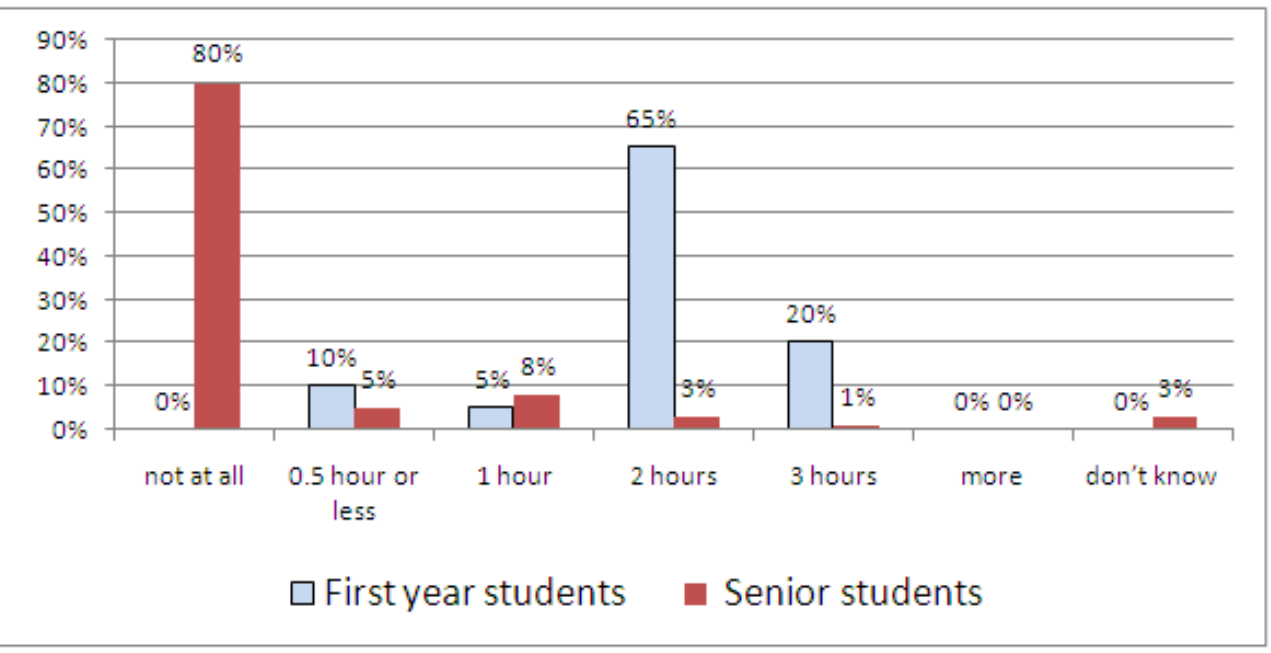

Figure 4: Average number of Facebook surfing a day for academic purposes

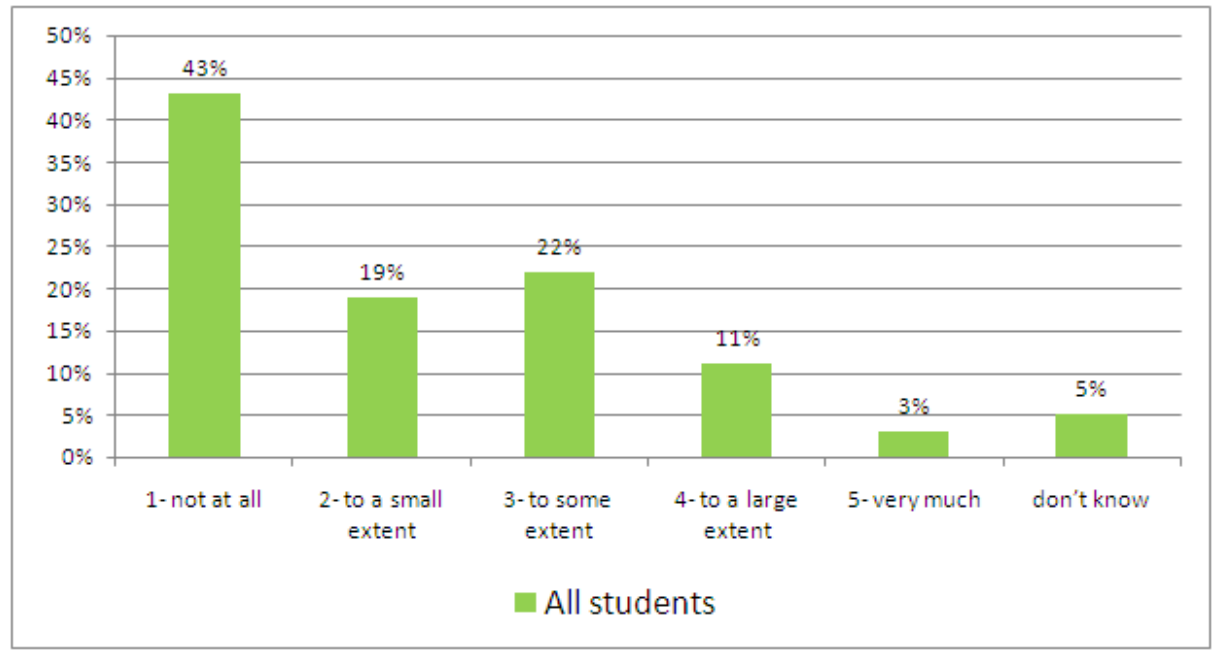

Figure 5: Usage of Facebook to get help in academic material

The students were asked (Q7) if they used Facebook in order to receive help with study materials from their friends or to get help before exams (Figure 5). They were also asked if the educational information and materials available on Facebook were of good quality (Q11) (Figure 6) and relevant for their studies (Q14) (Figure 7). The present study found that most of the students who had a Facebook account did not surf at all for academic purposes. Only 24\% (values 4 and 5 in Figure 6) of the students thought that the academic information published on Facebook is of high quality, and only 18\% (values 4 and 5 in Figure 7) thought the information is very relevant to their studies. In addition, it was found that only 25\% of the students believe that Facebook helped them significantly in their studies (Q8). 


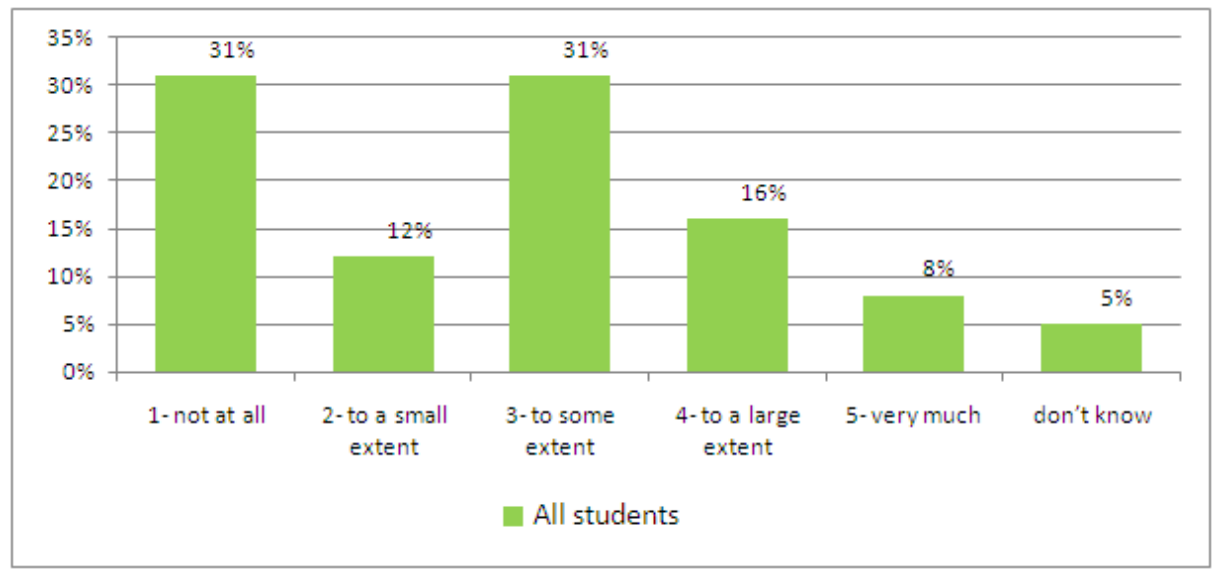

Figure 6: Perceived quality of academic materials on Facebook

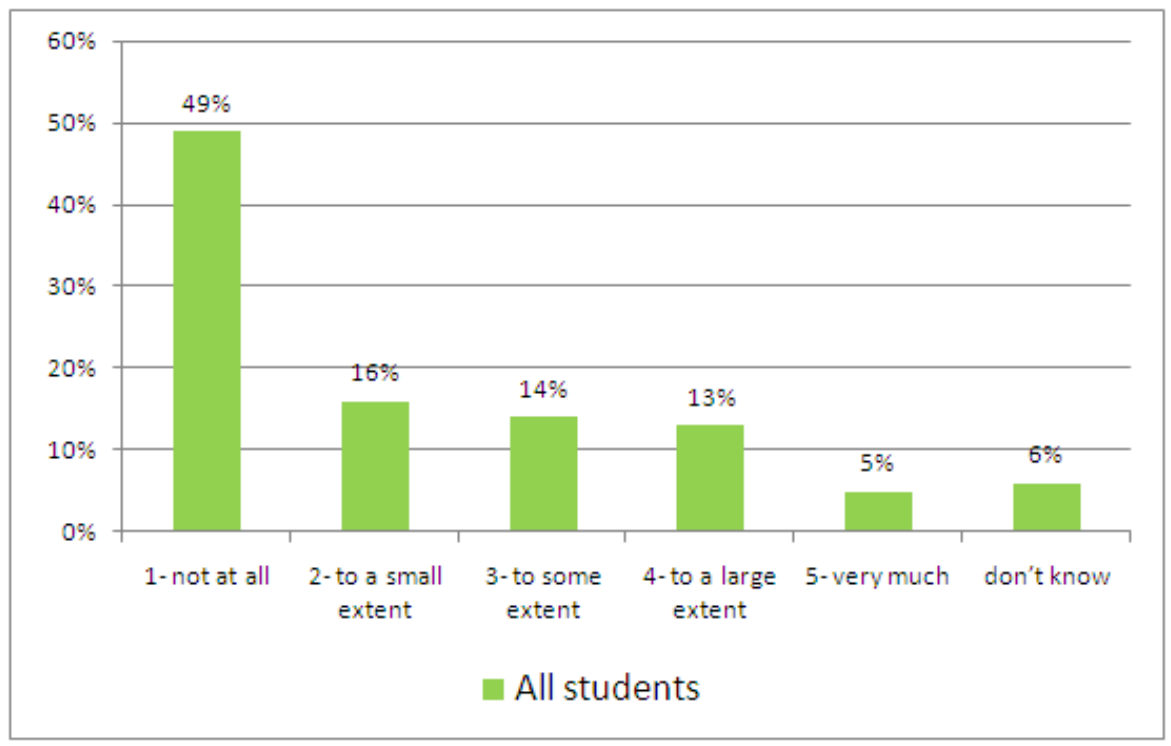

Figure 7: Perceived relevance of academic materials on Facebook

In addition, they were asked about the social impact of Facebook in their academic life. Figure 8 shows the distribution of the students' perception about the expansion of their social circle in the university due to Facebook, divided to first year students and senior students. A very big difference can be seen between these two populations, where the new students felt their social circle in the campus has been expanded as a result of using Facebook (Q9). 


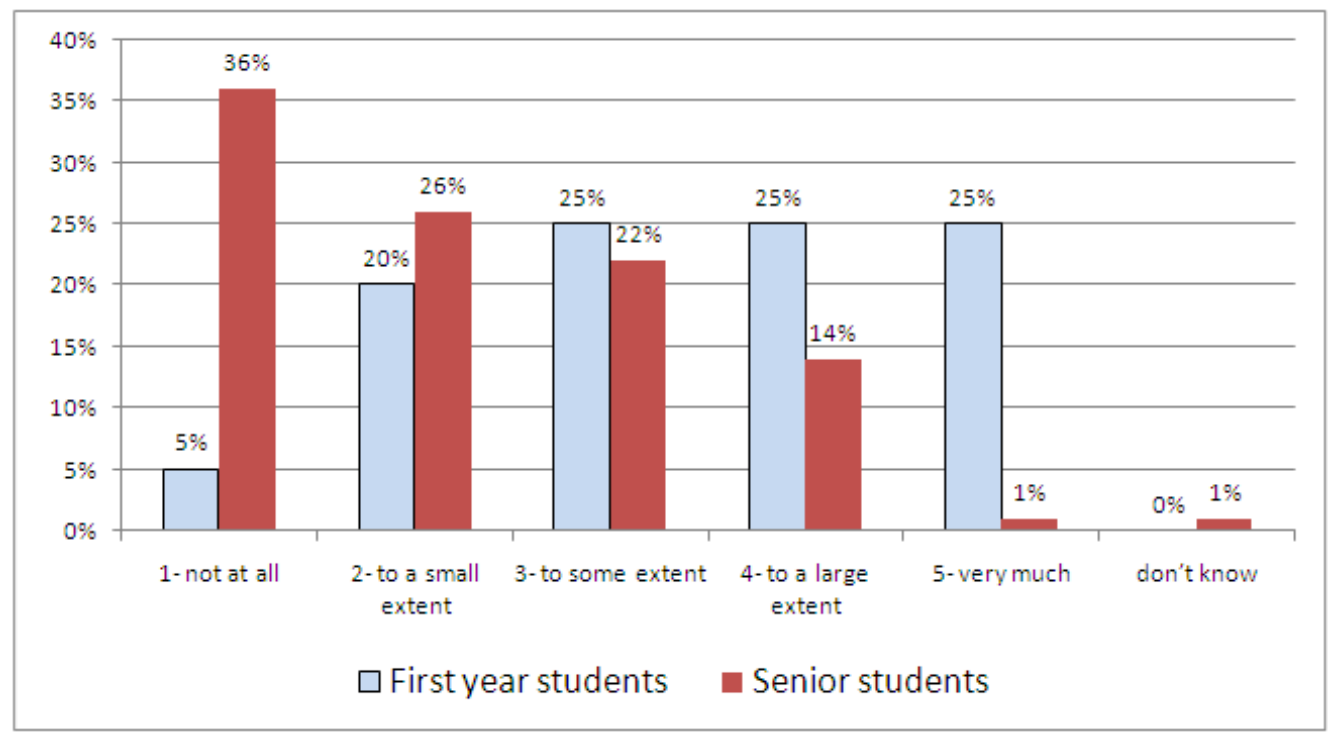

Figure 8: Perceived expansion of social circle in the campus due to Facebook

Most of the students having an account (84\%) spend some of their time in browsing photographs that other students and friends uploaded to the social network (Q18). These students were asked how long it would take them to go back to studies after this kind of interruption (Q20 \& Q21). Although most of the students (52\%) were able to immerse in studies immediately, almost half of the students need a "recovery" time of half an hour or more, as can be seen in Figure 9.

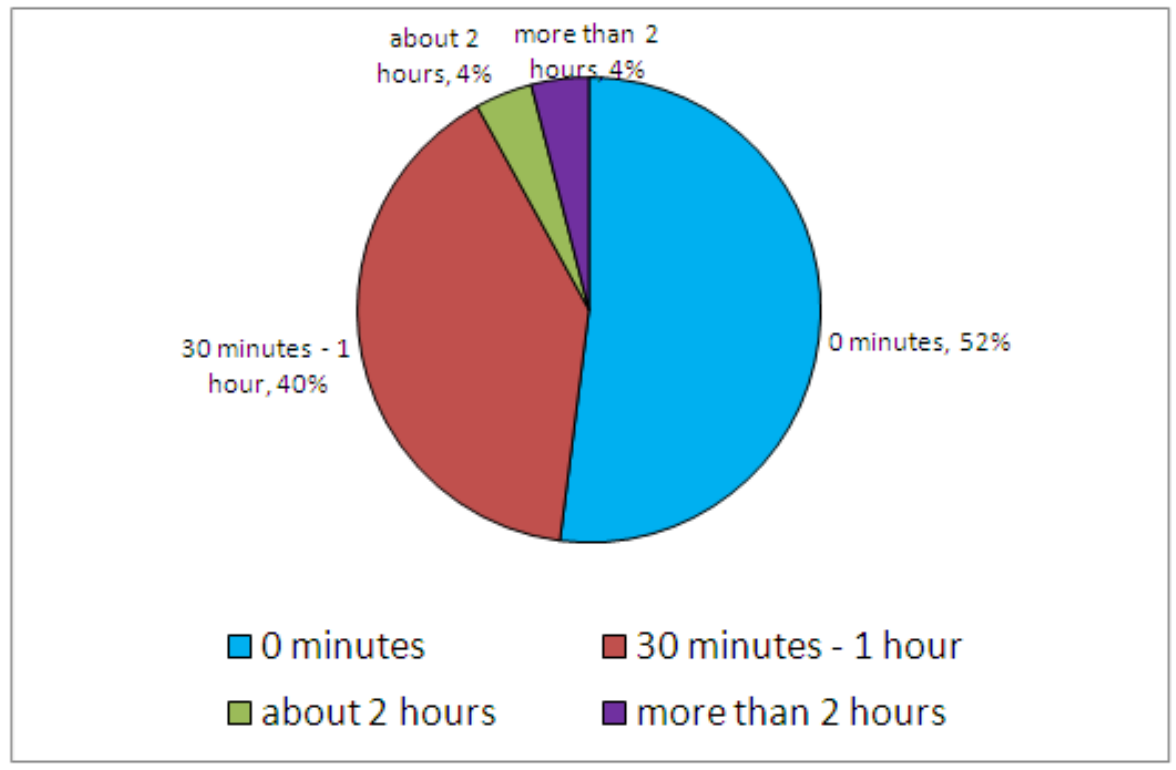

Figure 9: Time needed to get back to studies after browsing Facebook

\section{Facebook Pages Examination Results}

Facebook pages enable users to post comments and new issues and to become involved in the contents. This study reviewed seven Facebook pages of engineering departments, which will be called "A", "B", "C", etc., in order to keep anonymity. These pages contain information about social activities, educational materials, publications, announcements about "marathon" courses 
conducted before tests, etc. All examined Facebook pages were designated for undergraduate students. This examination was done in order to answer the research question RQ-c. Table 1 exhibits the findings: who had the initiative to open the page and did so, the number of threads (indicating the number of new subject posts in six months), the number of threads opened by students, the average number of posts per thread (i.e., the average number of responses for each new subject), and the ratio between academic and social threads.

Table 1: Examination of Facebook pages

\begin{tabular}{|l|l|l|l|l|l|l|}
\hline Institution & Initiator & $\begin{array}{l}\text { Number } \\
\text { of threads }\end{array}$ & $\begin{array}{l}\text { Number } \\
\text { of threads } \\
\text { opened by } \\
\text { students }\end{array}$ & $\begin{array}{l}\text { Average } \\
\text { number of } \\
\text { posts per } \\
\text { thread }\end{array}$ & $\begin{array}{l}\text { Number } \\
\text { of aca- } \\
\text { demic } \\
\text { threads }\end{array}$ & $\begin{array}{l}\text { Number } \\
\text { of social } \\
\text { threads }\end{array}$ \\
\hline A & Faculty & 15 & 0 & 0 & 7 & 8 \\
\hline B & $\begin{array}{l}\text { Student Asso- } \\
\text { ciation }\end{array}$ & 28 & 0 & 0.57 & 0 & 28 \\
\hline C & Faculty & 13 & 0 & 0.84 & 3 & 10 \\
\hline D & Faculty & 0 & 0 & 0 & 0 & 0 \\
\hline E & Faculty & 5 & 0 & 0 & 0 & 5 \\
\hline F & Faculty & 5 & 0 & 0 & 0 & 5 \\
\hline G & $\begin{array}{l}\text { Group of stu- } \\
\text { dents in sec- } \\
\text { ond year of } \\
\text { studies }\end{array}$ & 677 & 677 & 5 & 593 & 84 \\
\hline
\end{tabular}

Interestingly, most of the pages initiated by the study departments were static, with very little activity. On the other hand, the page opened by the students attending the second year was very active. This active Facebook group published most of the contents related to the learning process of the department, such as important publications (before tests), summaries of lessons, tests, questions and answers about exercises, etc.

\section{Discussion}

In order to answer our first research question (RQ-a), the cost and benefits perceived by the students who use Facebook during their studies were deduced from their answers to the questionnaire. While analyzing the students' answers, differences between first year and senior students are shown, answering the RQ-b.

\section{The Benefits of Using Facebook}

The benefits obtained from the use of an information system can be defined as tangible and intangible benefits.

\section{Tangible benefits}

Getting academic information and support. When studies are estimated as difficult and challenging there is a need for additional information and support in the learning process, in order to succeed. When the studies are perceived as simple it is not reasonable to assume that students will need additional information and support. For engineering students, who often estimate their studies as difficult (89\% of the students participating in our study), a vast variety of high quality academic information accessible through Facebook, either from the study program's page or from friends, can positively affect their success in exams. Students who have access to relevant and focused information have the potential to get good grades and pass their exams the first time, 
without needing to repeat the exam or the course. This situation saves time that can be invested in work hours to earn some money and also prevents expenses for private lessons. Hew (2011) reviewed the use of Facebook among students and found that the academic use of Facebook is minimal. Pempek et al. (2009) reinforced these findings, revealing that only $17 \%$ of the students use Facebook to communicate with each other for academic purposes. The present study found that only 35\% of engineering students use Facebook for educational purposes. Interestingly, the results differ between the first year and senior students - while $100 \%$ of the first year students use Facebook to some extent for academic purposes, only $17 \%$ of the senior students do so. These results lead to the conclusion that engineering students initially consider Facebook as a source of information and try to use it for information gathering. However, along the way they obviously get disappointed with the value they actually obtain; therefore, they change their attitude, do not consider it a part of academic success, and use this platform mostly for leisure and social purposes.

Referring to RQ-c, high education institutions may be more active in encouraging students to use Facebook for academic purposes, but unfortunately they do not do so, although they open accounts and dedicated pages on this social network (Boon \& Sinclair, 2009). To examine how academic institutions affect the use of Facebook by their students, the present study reviewed Facebook pages of several university departments. According to the results, all of the surveyed academic institutions actually have Facebook pages for their different departments, but it was almost impossible to find academic material or topics related to the educational process on those pages. Most of those pages completely lack students' activities. In one department of engineering, the students set up Facebook pages on their own. These pages are extremely active, compared to the study programs' pages; the activity is driven by students who publish large amounts of information related to the learning activities within their department. It should be noted that academic institutions have other alternative ways to reach their students, like forums and blogs, which are more active than their Facebook pages.

Academic relationships between students. Facebook allows establishing relationships with other student; , thus, students can consult and get information from each other about lecture summaries, ask questions, etc. This information cannot be received in conventional ways, such as books. For example, a student studying for a physics exam and having difficulties in solving an exercise can get immediate help on Facebook from his classmates. This online help saves time and money. According to the results, 34\% of the students received some form of assistance from other students through Facebook, but only 13\% are significantly using Facebook in that matter. These results strengthen the findings of Hew (2011) who found that online students tend to discuss more about their personal life than about their studies. Moreover, according to the results of the present study only $25 \%$ of the students who got assistance felt that this significantly helped them (Q8).

Work search. Students want to get a job and work during their studies in order to financially maintain themselves. According to the results of the questionnaire, $42 \%$ of the students in engineering degree do work (Q29), and 84\% of those who do not look for a job during the studies (Q30). Ellison et al. (2007), who focused on the potential benefits of Facebook friends for students, found that Facebook might be rewarding in terms of jobs and internships. The value of this benefit can be converted to real money.

Based on the above stated research findings, it can be concluded that relationships between students via Facebook could contribute significantly to the learning process of engineering students if it was used more intensively for academic purposes. But now, this benefit is not a significant part of students' academic success; neither is it is a platform for career success nor for savings on private lessons, but it has a potential to be that. 
Time saving. If the educational content available on Facebook is significantly more accessible compared to other sources of information, it may save time in searching and can allow a student to use the remaining time for work. The results show that $16 \%$ of the respondents believe the information needed for their studies is accessible through Facebook, but a significant part of the students, 48\%, think that this is not the case (Q12). Moreover, only 20\% of the respondents estimate that Facebook may save a significant amount of time in searching for information needed for studies (Q13). Hence, Facebook is not perceived as efficient and as significantly more accessible compared to other sources of information. Therefore, this potential benefit is not meaningful for students.

\section{Intangible benefits}

Many social system elements are intangibles, for example, self-confidence, self-esteem, and enlargement of social circles. Ellison et al. (2007) focused on the benefits of Facebook friends among college students and found that there are great benefits among people with low selfesteem. In addition, Kalpidou et al. (2011) claimed that there is a negative correlation between the amount of time spent on Facebook and self-esteem and found that first year students have lower self-esteem in comparison to students of second year or higher. Orr et al. (2009) found that Facebook provides opportunities for social interactions that one tends to avoid otherwise. However, Pemek et al. (2009), who examined the experience of students on Facebook, found that only 17\% of the students use Facebook to communicate among themselves. Similar results were found in the present study; although only $17 \%$ of the students estimated they have expanded their circle of friends at the academic institution through Facebook (Q9), this result differs between the years (50\% in first year students, $15 \%$ senior students). In addition to social circle expansion on campus, Facebook is also a place to express and share thoughts and feelings about school. $53 \%$ of all students (70\% of the first year students) perceived Facebook as a good place for this purpose (Q10). The fact that students have a place where they can share thoughts and feelings about school may generate learning motivation among students. Therefore, it can be concluded that Facebook contributes to the sense of belonging among students, especially to those who have difficulties in socializing and low self-esteem, but it is not necessarily a mean for building friendships at the academic institutions.

\section{The Costs of Using Facebook}

The costs of using Facebook can be divided, as for any information system, into two phases:

(1) The establishment phase, where the user opens an account on the social network, uploads the initial files, photos, and data in order to build his/her profile and browses the network in order to find friends and groups to establish the connections to communicate with.

(2) The operational phase refers to the daily usage of the social network, where a user upgrades statuses and files, uploads posts, and especially browses and comments on other users' postings and photographs.

\section{Establishment phase costs}

When a student decides to open a Facebook account during his or her studies, it requires investing time to fill out some information, upload photos, and other content. According to the results, only $8 \%$ of the students created a Facebook account during their studies (Q15), and the costs, in terms of time are negligible, relative to the four years of studies because this activity is performed only once. The conclusion is that the establishment phase has no meaningful cost effect on students. 


\section{Operational phase costs}

One of the most important "costs" of using Facebook, for students whose studies are perceived as difficult, is the number of hours spent on it. Kalpidou et al. (2011) found that first year students have a high emotional connection to Facebook; hence, they spend more time using it. According to the present study, all first year students used Facebook, whereas $14 \%$ of the senior students did not use Facebook at all (Q5).

How much time each day do students invest on Facebook? Kalpidou et al. (2011) discovered that students use Facebook between one to two hours. The results of the questionnaire in this study revealed that $86 \%$ of engineering students spend at least an hour a day surfing on Facebook (Figure 3). More students are using Facebook between 3 to 6 hours per day during their first year, compared to other students (15\% in first year, compared to $11 \%$ in second year or later). In addition, 15\% of the first year students spend 6 to10 hours on Facebook per day, compared to 5\% of the senior students. Students in the first year spend more time on Facebook than senior students, in accordance with prior research results. Part of this cost could have been translated into benefits, if the Facebook surfing was for academic purposes.

How much quality learning time students 'lose' per day due to distractions caused by the use of Facebook? In addition to the time spent surfing Facebook, it is also interesting to consider the "recovery" time, meaning the time that is not used to study after the use of Facebook, because of the emotional impacts of Facebook on a student. The extent of influence depends on whether students agree that Facebook has an impact on their feelings. In order to find if Facebook can stimulate feelings such as yearning (for free time, leisure, etc.) students were asked if they watch pictures of their friends having fun and traveling (Q18). The results show that $88 \%$ of the students use to watch pictures of friends. These results are very high compared to Pempek et al. (2009) who found that only $35 \%$ of the students claimed they spend time watching photographs. This may be explained by the worldwide expansion of Facebook in the last years, especially as a means for sharing pictures with friends. Our study also found that $73 \%$ of the students agreed that viewing photos of friends makes them long for free time (Q19). Moreover, $48 \%$ of the students estimate that the amount of time it takes to continue with their academic assignments is between 30 minutes and two hours (Figure 9). In summary, there is a significant period of time that can be utilized for studies, but instead, it is utilized for surfing Facebook. Beyond that, Facebook has effects on students even after using it, because Facebook has the ability to arouse emotions, and these feelings inhibit the learning process significantly. If students would decide to reduce their use of Facebook, they could use this time to work and earn money, as well as for additional learning hours during the day (which increases the chances of getting better grades, and by raising their average grade they could expect to get, maybe, a better job).

In order to check whether there are any Internet costs that can be ascribed to Facebook, the students were asked whether they pay for Internet by time (Q27) and how long they surfed on Facebook. The cost of the Internet for using Facebook is both for educational and social use, but we could see the social use affects the educational one. Therefore, it is interesting to discover the costs spent on the infrastructure. Financial costs include the payment for surfing Facebook through a computer and also from mobile phones. Based on the results of the present study, 52\% of the students own a mobile device that supports Facebook (Q22) but only 33\% use it (Q23). Only $4 \%$ of the students who use Facebook on their mobile phone estimate they spend significant time on it (Q25). Moreover, only 7\% of the students pay for Internet according to the usage time, and none of them believe that Facebook affects their Internet expenses (Q28). It can be added that only $8 \%$ of the students who purchased a mobile phone supporting Facebook see the social network as a reason or motivation for this purchase (Q24). The extension of social network usage may cause this reason to grow over the years, as it can be seen by the $57 \%$ of positive answers that this will be a reason for purchasing a new mobile phone (Q26). In spite of that, when pur- 
chasing a phone, the customer is tied to a contract with the mobile company for three years, so most of the students have no option to purchase a new phone with these capabilities. Therefore, as for now, Facebook cannot be ascribed to the cost of the purchase of a mobile phone, but this can change. From the points presented above, it can be concluded that Facebook does not increase the Internet cost by much.

One of the research questions (RQ-d) was whether the students' average grades increased or decreased because of the use of Facebook. One indication can be perceived if (1) there is no significant difference in the perceived difficulty level of engineering studies between first year students and senior students (to avoid external effects on the result) and (2) the student did not use Facebook at all or was not registered to Facebook during some period but used Facebook in other periods. According to the results (Q1, Q2, Q15, Q16, Q17), the students did not perceive differences in the level of difficulty between the years, and only $8 \%$ of the students who started their studies without Facebook accounts registered later. Only one respondent of this group had a significant decrease in the average grade. Therefore, according to these results, it can be concluded that there is no direct connection between Facebook use and a decrease in the average grade, but this conclusion must be further examined.

\section{Conclusion}

Although Facebook is, in the first place, an infrastructure for socialization and not a learning platform, it can combine both. Facebook can hold significant benefits for students, but the use of Facebook can also damage the learning process and that should not be ignored.

Facebook was found particularly important among first year students (RQ-b), and meeting new people on campus can be done easily by using the Facebook network (that was, after all, the initial goal of Facebook). In addition, it should be noted that Facebook was not designed to be a learning platform, but in some study programs Facebook was found to be particularly active (i.e., Table 1, institution $\mathrm{G}$ ) for the students' learning process.

The main resource for students in their learning process is time, and this resource is negatively affected by Facebook usage. Facebook offers students many temptations that waste a lot of their precious time, and, according to the findings in the present study, this resource is affected even after spending time on Facebook, because users can be influenced by contents seen on Facebook.

Students could use Facebook as a platform to exchange academic information. The fact that some of the benefits that Facebook holds for students can be acquired by using different online forums hosted by academic institutions should be considered. These forums were built to be a platform for sharing learning content and information among students but were not meant to be a platform for social communication. Facebook may combine both.

At the present time, academic institutions do not have an effect on students' Facebook usage. These institutions understood that almost one hundred percent of the students spend time on Facebook, and, therefore, they opened pages on this infrastructure. But, as shown in this paper, they do not succeed in transforming these pages to a useful tool for the students, so they are inactive and unused. Academic institutions are strongly invited to change this attitude and learn from the success of the Facebook pages opened by students groups.

If students were able to limit their usage of Facebook only to get in touch with acquaintances on campus and to share academic information, there is no doubt that Facebook could offer them benefits, such as creating a sense of social belonging and security and contributing to the learning process. 
In summary, Facebook may have a significant impact on students' learning process, both positively and negatively, and viability depends on the student's academic year, amount of Facebook use, and the purpose of the use.

In the future, apparently, more and more students will use Facebook and the time students spend on Facebook will increase rapidly, as it has in the previous 6 years. Technology is evolving rapidly with Facebook by its side and is likely to offer more and more applications and attractive user interfaces through ubiquitous devices that may distract students from the learning process.

\section{Future Research}

This research defined the costs and benefits of using Facebook, but did not measure them. Future research will try to measure the different components in order to decide whether the usage of the social network is worthwhile for students. Moreover, it is interesting to find whether there are differences in the profitability of usage for different study programs. Future research will enlarge the sample population, by adding more students from different study programs.

\section{References}

Boogart, V. R. M. (2006). Uncovering the social impacts of Facebook on a college campus. Master's thesis, Department of Counseling and Educational Psychology, Kansas State University.

Boon, S., \& Sinclair, C. (2009). A world I don’t inhabit: disquiet and identity in Second Life and Facebook. Educational Media International, 46(2), 99-110.

Ellison, N. B., Steinfield, C., \& Lampe, C. (2007). The benefits of Facebook "friends:" Social capital and college students' use of online social network sites. Journal of Computer-Mediated Communication, 12(4), article 1.

Facebook Newsroom. (2012). Fact sheet - Statistics. Retrieved on 28 Feb 2012 from http://newsroom.fb.com/content/default.aspx?NewsAreaId=22

Gonzales, A .L.. \& Hancock, J. T. (2011). Mirror, mirror on my Facebook wall: Effects of Facebook exposure on self-esteem. Cyberpsychology, Behavior \& Social Networking, 14, 79-83.

Gunasekaran, A., Ngai, E. W. T., \& McGaughey, R. E. (2006). Information technology and systems justification: A review for research and applications. European Journal of Operational Research, 173(3), 957-983.

Hendrix, D., Chiarella, D., Hasman, L., Murphy, S., \& Zafron, M. (2009). Use of Facebook in academic health sciences libraries. Journal of the Medical Library Association, 97(1), 43-46.

Hew, K. F. (2011). Students' and teachers' use of Facebook. Computers in Human Behavior, 27(2), 662676.

Hewitt, A., \& Forte, A. (2006). Crossing boundaries: Identity management and student/faculty relationships on the Facebook. Poster/Extended Abstract. Computer Supported Cooperative Work (CSCW), Banff, Canada, November 4-8.

Kalpidou, M.. Costin, D., \& Morris, J. (2011). The relationship between Facebook and the well-being of undergraduate college students. Cyberpsychology, Behavior, and Social Networking, 14, 183-189.

Kirkpatrick, D. (2010). The Facebook effect: The inside story of the company that is connecting the world. New York: Simon \& Schuster.

Kuss, D. J., \& Griffiths, M. D. (2011). Addiction to social networks on the internet: A literature review of empirical research. International Journal of Environment and Public Health, 8, 3528-3552. 
Lampe, C., Ellison, N., \& Steinfield, C. (2006). A face(book) in the crowd: Social searching vs. social browsing. CSCW '06: Proceedings of the 2006 20th Anniversary Conference on Computer Supported Cooperative Work, ACM Press, 167-170.

Mack, D., Behler, A., Roberts, B., \& Rimland, E. (2007). Reaching students with Facebook: Data and best practices. Electronic Journal of Academic and Special Librarianship, 8(2). Retrieved November 4, 2011 from http://southernlibrarianship.icaap.org/content/v08n02/mack_d01.html

Madge, C., Meek, J., Wellens, J., \& Hooley, T. (2009). Facebook, social integration and informal learning at university: It is more for socialising and talking to friends about work than for actually doing work. Learning, Media and Technology, 34, 141-155

Muise, A., Christofides, E., \& Desmarais, S. (2009). More information than you ever wanted: Does Facebook bring out the green-eyed monster of jealousy? CyberPsychology \& Behavior, 12(4), 441-444.

Orr, E. S., Sisic, M., Ross, C., Simmering, M. G., Arseneault, J. M., \& Orr, R. R. (2009). Rapid communication: The influence of shyness on the use of Facebook in an undergraduate sample. $\mathrm{Cy}$ berPsychology \& Behavior, 12(3), 337-340.

Pempek, T., Yermolayeva, Y., \& Calvert, S. L. (2009). College students' social networking experiences on Facebook. Journal of Applied Developmental Psychology, 30(3), 227-238.

Raacke, J., \& Bonds-Raacke, J. (2008). MySpace and Facebook: Applying the uses and gratifications theory to exploring friend-networking sites. Cyber psychology \& Behavior, 11(2), 169-174.

Ulusu, Y. (2010). Determinant factors of time spent on Facebook: Brand community engagement and usage types. Journal of Yasar University, 18(5), 2949-2957.

Vivian, R. (2011). University students' informal learning practices using Facebook: Help or hindrance? In: enhancing learning through technology. Education unplugged: Mobile technologies and Web 2.0. Communications in Computer and Information Science, 177, 254-267.

Wheeler, T. (2011). Facebook fatalities: Students, social networking, and the first amendment. Pace Law Review, 31(1), 182

\section{Appendix}

The questionnaire included questions about the students' usage of Facebook:

Q1: What school year are you?

Q2: To what extent would you define your studies as difficult?

Q3: How many times a week you can devote to leisure activities? (Movies, pub, visiting friends - or any other activity)

Q4: Do you have a Facebook account?

Q5: How many hours per day do you usually spend on surfing Facebook pages?

Q6: How many of these hours are for learning purposes?

Q7: In what extent do you get help from other students for learning purposes through Facebook?

Q8: If you were assisted by other students through Facebook, in what extent did you feel that those students really helped you?

Q9: Did you enlarge your friendship circle in your university thanks to Facebook?

Q10: How much do you estimate that Facebook is a place that allows students to express thoughts and feelings about school?

Q11: What do you think about the quality of learning information published on Facebook?

Q12: How much of the information you need for your studies is accessible through Facebook?

Q13: Could Facebook save you time searching for information that you need for your studies? 
Q14: Do you estimate that you receive information relevant to your studies via Facebook?

Q15: If you have a Facebook account, did you open it during the school or before?

Q16: What is your current average grade?

Q17: If you opened a Facebook account during the studies, what your average grade was before opening the account?

Q18: As you browse Facebook, do you watch pictures of friends enjoying or traveling?

Q19: Does it make you yearn for leisure time or vacations or leisure time?

Q20: To what extent would you define your learning ability immediately after watching your friends' pictures on Facebook?

Q21: How long does it take you to achieve effective learning after viewing your friends' pictures on Facebook?

Q22: Do you own a mobile phone that supports browsing Facebook?

Q23: If so, do you browse Facebook via your mobile phone?

Q24: If you own a mobile phone that supports Facebook, in what extent do you estimate that you purchased it so you could surf Facebook?

Q25: How often do you estimate you browse Facebook via your mobile phone?

Q26: If you don't own a mobile phone that supports Facebook, do you have intentions to buy a device that does so in the future?

Q27: Do you pay for your Internet services according to the amount of time you surf?

Q28: If so, how much do you estimate that Facebook affects your Internet expenses?

Q29: Do you work during your studies?

Q30: If not, do you want to combine work with studies?

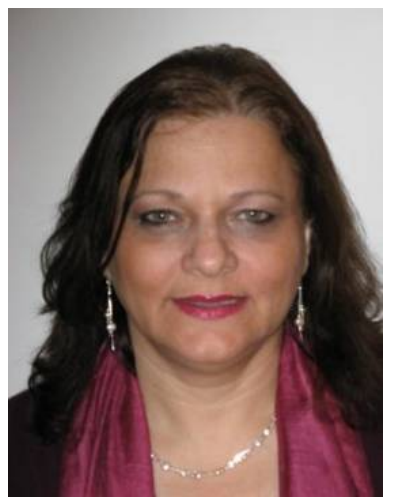

\section{Biographies}

Dr. Ruti Gafni holds a PhD from Bar-Ilan University, Israel (in the Business Administration School), focusing in Information Systems. She also holds an M.Sc. from Tel Aviv University and a BA (Cum Laude) in Economics and Computer Science from Bar-Ilan. She has more than 30 years of practical experience as Project Manager and Analyst of information systems. She teaches the Management and Economics MBA program, both at the Open University of Israel and at Netanya Academic College, and the Management of Information Systems BA program at Tel Aviv-Yaffo Academic College.

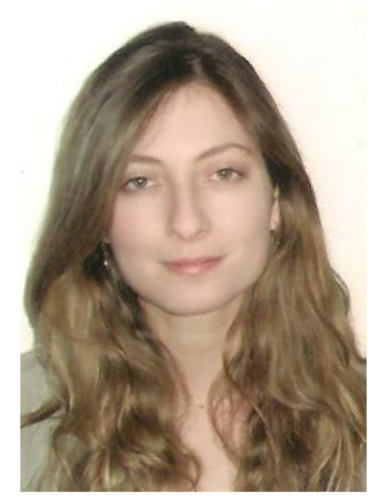

Moran Deri is an undergraduate student (with honor) in the Management of Information Systems BA program at Tel Aviv-Yaffo Academic College. 